\title{
A ESTRUTURA E A ORGANIZAÇÃO DA EDUCAÇÃO BÁSICA NA ESPANHA: SUAS DIFERENÇAS E SIMILITUDES COM A EDUCAÇÃO BÁSICA BRASILEIRA
}

\author{
LA ESTRUCTURA Y ORGANIZACIÓN DE LA EDUCACIÓN BÁSICA EN \\ ESPAÑNA: SUS DIFERENCIAS Y SIMILITUDES CON LA EDUCACIÓN BÁSICA \\ BRASILEÑA
}

\begin{abstract}
THE STRUCTURE AND ORGANISATION OF BASIC EDUCATION IN SPAIN: THEIR DIFFERENCES AND SIMILARITIES WITH THE BRAZILIAN BASIC EDUCATION
\end{abstract}

RESUMO: O objetivo desse artigo é, inicialmente, descrever como se organiza e como se estrutura a Educação Básica espanhola para, em seguir, fazer comparações que nos mostrem as semelhanças e as diferenças com a organização e com a estrutura da Educação Básica brasileira. Ao final, baseados em nossa descrição, fazemos alguns apontamentos que podem ajudar a compreender os principais problemas educacionais brasileiros, bem como colaborar para a elaboração de propostas que visem resolver (ou minimizar) esses problemas.

PALAVRAS-CHAVES: Estrutura e organização da educação básica espanhola. Estrutura e organização da educação básica brasileira. Políticas públicas de educação.

RESUMEN: El objetivo de este artículo es, inicialmente, describir cómo se organiza y cómo se estructura el sistema español de la educación básica, y, a seguir, hacer comparaciones que nos muestran las similitudes y diferencias con la organización y la estructura de el sistema brasileño de la educación básica. Al final, basado en nuestra descripción, hacemos algunas notas que pueden ayudar a comprender los principales problemas educativos brasileños, así como colaborar en la preparación de propuestas encaminadas a resolver (o minimizar) estos problemas.

PALABRAS CLAVES: Estructura y organización de la educación básica española. Estructura y organización de la educación básica brasileña. Políticas publicas educativas.

ABSTRACT: the aim of this article is, initially, describe how is organized and how to structure the Spanish system for basic education, to follow, making comparisons that show us the similarities and differences with the organization and the structure of the Brazilian system basic education. In the end, based on our description, we do some

${ }^{1}$ Universidade Estadual Paulista (UNESP), Assis - SP - Brasil. Professor Associado do Departamento de Educação - UNESP/Assis. Docente do Programa de Pós-graduação em Educação da UNESP/Marília. ORCID: <http://orcid.org/0000-0003-2254-0692>. E-mail: cbrandao@assis.unesp.br 
notes that might help us understand the main Brazilian educational problems, as well as collaborate for the preparation of proposals aimed at resolving (or minimize) these problems.

KEYWORDS: Structure and organization of the Spanish system of basic education. Structure and organization of the Brazilian system of basic education. Public policies for education.

\section{Introdução}

O objetivo do presente artigo é o de comparar a estrutura e o funcionamento da Educação Básica espanhola e da Educação Básica brasileira ${ }^{2}$. Para tanto utilizaremos, como método de pesquisa e de análise, a denominada metodologia da Educação Comparada. No decorrer do presente texto, pretendemos fazer comparações que nos mostrem as semelhanças e as diferenças entre uma e a outra estrutura educacional, entendidas (tanto a espanhola como a brasileira) como sistemas de ensino. Ao final, baseados em nossa descrição e em nossa análise, faremos alguns apontamentos que podem ajudar a compreender os principais problemas educacionais brasileiros, bem como colaborar para a elaboração de propostas que visem resolver (ou minimizar) esses problemas.

A opção por elaborarmos nosso artigo em um formato de "idas e vindas" possui o objetivo de, utilizando-se da metodologia dos estudos e pesquisas da Educação Comparada, fazer com que o presente texto não se configure como um texto excessivamente descritivo, mas, essencialmente, analítico, que permita ao leitor, ao seu final, ter uma noção geral dos sistemas de ensino espanhol e brasileiro.

Segundo Carvalho (2014), os estudos no campo da Educação Comparada são relativamente recentes, visto que as "primeiras obras consideradas de caráter científico nesse campo datam do final do século XIX". Segundo essa autora, esse "surgimento tardio explica-se pelo fato de que seu objeto são os sistemas nacionais de ensino, os quais passaram a ser criados no século XIX". Assim, o "processo de criação dos sistemas de ensino, ao longo do século XIX foi, portanto, a base da construção dos estudos comparados em educação." (CARVALHO, 2014, p. 130).

${ }^{2}$ Sobre a estrutura e organização da educação brasileira, ver, por exemplo, Davies (2004). 
Para Franco (1992), a importância de se realizar estudos comparados, entre outros motivos, está em "conhecer os outros [...] e, nesse ato, aprofundar o conhecimento de si mesmo e do outro, assim, o

O princípio da comparação é a questão do outro, o reconhecimento do outro e de si mesmo pelo outro. A comparação é um processo de perceber as diferenças e semelhanças e de assumir valores nessa relação de mútuo reconhecimento. Trata-se de entender o outro a partir dele mesmo e, por exclusão, se perceber na diferença. (FRANCO, 1992, p. 14)

Porém, para essa autora, comparar não significa homogeneizar, muito pelo contrário, a comparação, com a respectiva percepção das diferenças, deve se dar "sob o postulado da igualdade de direitos à sobrevivência, à política, à cultura”. Assim, se comparamos sociedades em que tais direitos são significativamente díspares, encontraremos, necessariamente, realidades igualmente díspares, desfazendo-se assim, a "homogeneidade pastosa da igualdade abstrata" (FRANCO, 1992, p. 33).

Nesse mesmo sentido, Kandel foi um dos primeiros autores no campo da Educação Comparada, nas primeiras décadas do século $\mathrm{XX}$, a ressaltar que, para que possamos compreender os sistemas educativos nacionais, devem "ser levadas em consideração as forças políticas, sociais, culturais" assim como "o caráter nacional” que determinam suas particularidades (KANDEL, 1933, p. 27).

Tendo, por um lado, as realidades locais (nacionais) e, por outro lado, o incisivo processo de globalização, especialmente econômica e cultural, presente nesse início de século XXI, quais seriam então os desafios atuais para os estudiosos que se utilizam da metodologia da educação comparada para realizar pesquisas no campo educacional?

As respostas para essa questão, apesar de pontualmente diferentes, convergem para uma mesma direção. Para Carvalho, o "processo de reorganização nos sistemas educativos nos diferentes países, segundo padrões sem fronteiras" é o que confere uma "nova importância à Educação Comparada e coloca seus investigadores diante de novos desafios." (CARVALHO, 2014, p. 135).

Já para Lima e Afonso, o atual contexto exige do pesquisador que o mesmo seja capaz de "identificar os tópicos recorrentes, as semelhanças nas retóricas produzidas e nas soluções propostas, mas também as dessemelhanças significativas e os traços particulares de âmbito nacional", evitando-se "a reprodução descontextualizada das análises e críticas produzidas noutros contextos", assim como também deve se evitar a 
excessiva valoração de fatores locais. Esses autores sugerem que a postura teóricometodológica do pesquisador em Educação Comparada deve ser a de identificar aquilo que é comum ou idêntico e, simultaneamente, aquilo que é único e específico (LIMA; AFONSO, 2002, p. 7-8).

No caso especifico dessa nossa pesquisa, que tem por objetivo comparar os sistemas de ensino de um país europeu (Espanha) e de um país da América do Sul (Brasil), que significa dizer que estaremos comparando o sistema de ensino de um país considerado desenvolvido, pertencente ao chamado "Primeiro Mundo" e um país considerado "em desenvolvimento", pertencente ao chamado "Terceiro Mundo", consideramos necessário ressaltar algumas considerações de Franco (1992) para a análise de situações análogas.

Para essa autora,

[...] a questão dos estudos comparados e da educação dos países dependentes, comparada aos sistemas educacionais dos países avançados, coloca-se, fundamentalmente, como a análise do produto de uma situação assimétrica de dominação/dependência, que se qualifica pelo desenvolvimento desigual e combinado dos países dependentes, sob a estratégia da expansão da acumulação do capital transnacionalizado. (FRANCO, 1992, p. 33)

Assim, seguindo o raciocínio dessa autora, o primeiro ponto que merece toda a nossa atenção é enxergarmos (e compreendermos) a "distância dramática que nos separa e separa nossos países e nossa educação dos países economicamente desenvolvidos". O segundo ponto é entendermos que, em certo sentido, "uns e outros são sistemas incomparáveis, na medida em que são frutos de processos históricos particulares, de trajetórias singulares, não obstante suas semelhanças.” (FRANCO, 1992, p. 34-35).

Para resolvermos a questão posta acima, a questão de compararmos o que, em certo sentido (segundo Franco), é incomparável, voltamos a nos apoiar em Carvalho (2014), que propõe que as pesquisas em Educação Comparada tenham como pressuposto teórico-metodológico a perspectiva dialética. Segundo essa autora, por meio da utilização dessa perspectiva

se pode esclarecer o que engendra o próprio processo de globalização, o que articula ou dissolve o local, o nacional e o global. Ela favorece a elucidação das mediações e interações dinâmicas, mostrando o lugar que os fatores locais ocupam no movimento mais geral da sociedade e, ao mesmo tempo, o que há de universal no particular, bem como as 
forças contraditórias atuantes nesse movimento relacional. (CARVALHO, 2014, p. 139).

Após essa introdução, na qual procuramos discutir o nosso referencial teóricometodológico para a análise da estrutura e funcionamento dos sistemas educacionais espanhol e brasileiro, nosso próximo passo é a descrição e respectiva análise das mesmos, o que faremos no tópico seguinte.

\section{A educação na Espanha: estrutura e organização.}

A educação espanhola é regida pela LOMCE (Ley Orgánica para Mejora de la Calidad Educativa - Ley Orgánica 8/2013, de 9 de dezembro de 2013), denominada popularmente Ley Wert, por conta de ter sido o Ministro da Educação, Cultura e Esporte, José Ignacio Wert, do governo do Primeiro-ministro Mariano Rajoy, que a propôs. Essa lei modifica a Ley Orgánica de Educación no 2 de 3 de maio de 2006 (LOE). Podemos dizer que a LOMCE e a LOE espanhola são, em seu conjunto, equivalentes a Lei de Diretrizes e Bases da Educação nacional, a LDB brasileira (Lei ${ }^{\circ}$ $9.394 / 96)^{3}$.

De maneira resumida, já que não se trata do objetivo principal desse artigo, os principais objetivos da LOMCE, que reformou a educação espanhola, são reduzir a taxa de evasão escolar, melhorar os resultados da educação espanhola nas avaliações internacionais (principalmente no PISA - Program for International Student Assessment), melhorar o índice de alunos considerados excelentes (segundo os parâmetros do PISA), aumentar o número de alunos que terminam com êxito a Educação Secundária obrigatória, melhorar a empregabilidade e estimular o espírito empreendedor dos estudantes espanhóis.

Os princípios sobre os quais essa reforma se assenta são, fundamentalmente, o aumento da autonomia dos centros educacionais (escolas), o reforço da capacidade de gestão da direção desses centros, a melhoria dos resultados nas avaliações externas de larga escala ao fim de cada etapa formativa, a racionalização da oferta educativa e a flexibilização das trajetórias educativas.

Além desses princípios, há que se destacar três âmbitos sobre os quais a LOMCE tem especial incidência com vistas a transformação do sistema atual educativo

${ }^{3}$ Sobre as discussões sobre a educação espanhola antes da Ley Wert, para situar em que contexto ela surge, ver, por exemplo, Cruz (2008). Sobre a lei brasileira (LDB), ver, entre outros, Brandão (2018). 
espanhol, quer sejam, as chamadas TIC's (Tecnologias da Informação e da Comunicação), o estímulo constante ao plurilinguismo (o ensino do espanhol como língua materna e, no mínimo, o ensino da língua inglesa), e a modernização da Formação Profissional ${ }^{4}$.

A educação básica espanhola é, assim como a Educação Básica brasileira, dividida em três níveis: Educação Infantil (0 a 6 anos), Educação Primária (7 a 12 anos) e Educação Secundária (13 a 16 anos). O conjunto formado pela Educação Primária e pela Educação Secundária espanhola é chamado de Educação Básica 5 .

Assim como a organização e estrutura da Educação brasileira, a Educação Infantil espanhola (0 a 6 anos) é subdividida em dois níveis, quer sejam, Educación infantil de primer ciclo (0 a 3 anos) e Educación infantil de segundo ciclo (4 e 5 anos). Assim como no Brasil, a Educación infantil de primer ciclo (0 a 3 anos) não é obrigatória. Não sendo obrigatório, esse nível de ensino (a Educación infantil de primer ciclo), em sua grande maioria, não é oferecido pelo setor público espanhol, fazendo com que a sua oferta seja, em grande medida, realizada pelo setor privado e com mensalidades que podem ser consideradas caras até para os padrões econômicos espanhóis 6 .

Um dos fatores que encarecem as mensalidades escolares da Educación infantil de primer ciclo na Espanha é que desde essa etapa escolar existe a definição legal da quantidade de alunos por sala (ou por professor/auxiliar). Nessa etapa inicial da vida escolar da criança um professor/auxiliar não pode ter sob seus cuidados mais que 8 crianças de 0 a 1 ano, 13 crianças de 1 a 2 anos ou 20 crianças de 2 a 3 anos.

A existência desses números objetivos na relação alunos/professor/auxiliar, faz com que, quando oferecida pelo setor público, o Estado tenha que contratar muitos professores/auxiliares, e, considerando que o orçamento público sempre é limitado, a

\footnotetext{
${ }^{4}$ Segundo pesquisas oficiais locais, apenas $30 \%$ dos jovens espanhóis possuem nível avançado (B2) em proficiência na língua inglesa.

${ }^{5}$ Neste texto, apenas para efeitos de uma melhor explanação didática e comparação dos sistemas educativos brasileiro e espanhol, quando utilizarmos a expressão "educação básica" espanhola totalmente com letras minúsculas, estaremos nos referindo ao conjunto formado pelos níveis de Educação Infantil, Educação Primária e Educação Secundária espanholas. Já, quando utilizarmos a expressão "Educação Básica" espanhola (com as iniciais em maiúsculo), estaremos nos referindo ao conjunto formado apenas pelos níveis Educação Primária e Educação Secundária espanhola.

${ }^{6}$ Segundo informações colhidas in loco, em torno de 300 Euros (aproximadamente R $\$ 1.000,00$ em fevereiro de 2015). Há que se ressaltar que o salário mínimo espanhol, na mesma época, era de 800 Euros, ou seja, a mensalidade de uma creche na Espanha equivale a, aproximadamente, 37,5\% do salário mínimo local. Os poucos centros educacionais públicos que oferecem a Educación infantil de primer ciclo cobram aproximadamente um terço desse valor (118 Euros, em fevereiro de 2015), porém, como dissemos, existem poucos centros com classes para essa faixa etária.
} 
consequência direta é a existência de um menor número de escolas. Já, quando essa etapa escolar é ofertada pelo setor privado, essa mesma determinação legal, que define o número máximo de crianças por sala (professor/auxiliar), encarece as mensalidades, pelo mesmo motivo ${ }^{7}$.

Quando passamos para a análise da Educación infantil de segundo ciclo (4 e 5 anos), equivalente espanhol à pré-escola brasileira, a relação quantidade de crianças por sala/professor passa a ser de, no máximo, 25 crianças por sala/professor. Na Espanha, essa etapa escolar também não é obrigatória, porém, o setor público oferece gratuitamente para todas as crianças espanholas. Como a cobertura estatal da demanda de vagas nessa etapa é total, praticamente inexiste pré-escolas privadas na Espanha.

Em termos gerais, a Educação infantil espanhola tem como princípios básicos a educação inclusiva e a co-educação (integração escola e família). Seus objetivos pedagógicos são o desenvolvimento da criança em permanente atenção às necessidades educacionais específicas e às dificuldades de desenvolvimento das crianças. Em termos pedagógicos (e práticos), a alfabetização propriamente dita das crianças espanholas se dá nessa etapa da vida escolar, na Educación infantil de segundo ciclo (4 e 5 anos).

A partir do ano que a criança completa 6 anos é que se inicia a Educação Básica espanhola propriamente dita. Essa etapa da escolarização na Espanha vai dos 6 aos 16 anos, dividida em dois níveis: a Educação Primária (dos 6 aos 12 anos) e a Educação Secundária (dos 12 aos 16 anos). A Educação Primária compreende 6 cursos (anos) acadêmicos e se organiza em 3 ciclos, cada um com 2 cursos (anos) acadêmicos, chamados de ciclo inicial (6, 7 e 8 anos de idade), ciclo médio (9 e 10 anos) e ciclo superior (11 e 12 anos). No interior desses ciclos formativos não existe reprovação e a Educação Primária espanhola é obrigatória e totalmente gratuita.

Em termos gerais, a finalidade da Educação Primária espanhola é a de proporcionar ao aluno uma educação que lhe permita desenvolver plenamente suas capacidades pessoais e sociabilidade, adquirir habilidades e competências relativas à expressão e compreensão das formas orais, a expressão escrita e a compreensão leitora, a matemática básica e o uso da novas tecnologias, a comunicação audiovisual, desenvolver a capacidade de esforça, de trabalho e de estudo, estimular o sentido

\footnotetext{
7 A Educación infantil de primer ciclo na Espanha, diferentemente da creche brasileira (apesar de equivalente em termos de faixa etária), não é um direito constitucional da mulher trabalhadora, como é no Brasil. Somado às questões econômicas que já descrevemos, podemos dizer que as crianças espanholas de 0 a 3 anos, em sua imensa maioria, não frequentam nenhuma instituição escolar, ou seja, "ficam em casa".
} 
artístico, a criatividade e a afetividade, conhecer os conteúdos básicos da história, da geografia e as tradições regionais ${ }^{8}$.

A segunda etapa da Educação Básica espanhola é a etapa denominada Educación Secundária Obligatoria (ESO). Assim como a Educación Primaria, essa etapa é gratuita e, como a própria denominação coloca, é obrigatória. Geralmente, se inicia no ano que o aluno completa 12 anos e termina aos 16 anos, sendo permitido que o jovem termine essa etapa até os seus 18 anos $^{9}$. É composta por 4 curso (anos) acadêmicos e possui, de forma geral, os mesmos objetivos pedagógicos que a Educación Primaria, claro que com o acréscimo e aprofundamento dos conteúdos ${ }^{10}$.

Essa etapa, a Educación Secundaria Obligatoria (ESO) espanhola, possui uma especificidade muito importante no contexto do sistema escolar educativo espanhol. Ao fim dela, se aprovado, o aluno obtém o título de Graduado em ESO (Educación Secundaria Obligatoria). Com o obtenção desse título (ESO), o aluno pode ingressar no bachillerato $^{11}$, ou em um ciclo formativo de grau médio de formação profissional ${ }^{12}$, ou em um curso de enseñanzas deportivas (desde que seja aprovado também em provas específicas de aptidão física) ${ }^{13}$, ou em cursos de artes plásticas ou desenho. Por outro lado, caso o aluno não consiga ser aprovado ao final da Educación Secundaria Obligatoria (ESO) ele passar a ter as opções que descreveremos abaixo, sempre em função da sua idade.

Se o jovem não aprovado ao final da Educación Secundaria Obligatoria (ESO) possui 16 anos de idade, ele pode ingressar em programas de qualificação profissional

\footnotetext{
${ }^{8}$ A questões regionais são, historicamente, muito fortes no contexto espanhol e, portanto, também muito fortes no contexto educativo espanhol. As Comunidades Autônomas (o equivalente aos Estados brasileiros), em termos de educação, podem legislar sobre os conteúdos regionais a serem ensinados e o fazem sempre no sentido da preservação da história e da cultura local. O exemplo mais significativo disso é que a maioria das Comunidades Autônomas, alfabetizam as crianças em espanhol e no idioma (dialeto) local (catalão, basco, galego, etc.).

${ }^{9}$ Há que se ressaltar que, no hemisfério norte, o ano letivo começa em setembro e termina em junho do ano civil seguinte.

${ }^{10}$ A Comunidade Autônoma da Catalunha, por exemplo, alfabetiza em catalão e somente na Educación Secundaria Obligatoria (ESO) é que o aluno vai aprender o idioma Castelhano.

${ }^{11}$ Os cursos de Bachillerato no sistema de educacional espanhol não são equivalentes aos cursos de bacharelado no Brasil. Mais à frente, no decorrer do texto, procuraremos descrever as diferenças.

${ }^{12}$ Para fins de melhorar compreensão do sistema educativo espanhol, vamos considerar, nesse artigo, as seguintes denominações e siglas: FP 0 (Formação Profissional de Nível Básico), FP I (Formação Profissional de Nível Médio) e FP II (Formação Profissional de Nível Superior).

${ }^{13} \mathrm{O}$ curso de enseñanzas deportivas no sistema educativo espanhol seria o equivalente aos cursos de Licenciatura em Educação Física no Brasil, porém, no contexto educacional espanhol eles são o que chamaríamos de "pós-médio" ou, para eles, "pre-grado". São cursos superiores mas não são ministrados nas Universidades.
} 
inicial (PQPI) ${ }^{14}$, em programas de formação de pessoas adultas ${ }^{15}$, em cursos de ensino de idiomas (a partir dos 14 anos o jovem pode estudar um idioma diferente do idioma cursado na Educación Secundaria Obligatoria) ${ }^{16}$, ou em curso de ensino elementar e profissional de música e dança ${ }^{17}$, desde que, nesse caso, ele também seja aprovado em provas de habilidades específicas.

Porém, se o jovem não aprovado ao final da Educación Secundaria Obligatoria (ESO) já completou 17 anos de idade, ele pode se encaminhar para um ciclo formativo de grau médio ${ }^{18}$, se aprovado em prova de acesso para o mesmo. Por fim, se o jovem não aprovado ao final da Educación Secundaria Obligatoria (ESO) já possui 18 anos, ele pode fazer uma "prova livre" para a obtenção do título de graduado em Educación Secundaria Obligatoria (ESO) ${ }^{19}$. Somente quando o aluno termina essa etapa (ou a Educación Secundaria Obligatoria ou um ciclo formativo de grau médio) é que o aluno pode ingressar no mundo do trabalho.

A partir do término, com sucesso, da Educación Secundaria Obligatoria (ESO), ou seja, a partir do início do caminho para a Universidade (mas não só para ela, visto que ao fim da Educación Secundaria Obligatoria não se inicia a Universidade, como no Brasil), é que aparecem as maiores diferenças, em termos de percursos e de características, entre o sistema educacional espanhol e o brasileiro.

Como já descrevemos alguns parágrafos atrás, ao obter o título da ESO (Educación Secundaria Obligatoria), o jovem pode fazer um curso de Bachillerato nas mais diversas áreas do conhecimento, ou ingressar em um curso de formação profissional de nível médio (FP I), ou ingressar em um curso de enseñanzas deportivas, ou de artes plásticas, ou de desenho. Esses cursos são considerados, no contexto educacional espanhol, como cursos superiores e, além disso, o mercado de trabalho espanhol considera que os jovens egressos desses cursos já estão aptos para trabalhar como profissionais de nível superior.

Há que se destacar que os chamados cursos de Bachillerato do sistema educativo espanhol possuem uma forte característica de cursos eminentemente propedêuticos, servindo assim, como uma forma de preparação para a Universidade nas mesmas áreas

\footnotetext{
${ }^{14}$ Essa é a sigla oficial dos programas de Formação Profissional de Nível Básico (que aqui denominamos de FP 0), que é o equivalente, no Brasil, aos cursos profissionalizantes de nível básico.

${ }^{15}$ Cursos de formação inicial de professores para trabalhar com adultos.

${ }^{16}$ Cursos de formação inicial de professores de idiomas.

${ }^{17}$ Cursos de formação inicial de professores de dança e de música.

${ }^{18} \mathrm{O}$ equivalente aos cursos profissionalizantes de nível médio brasileiros.

${ }^{19} \mathrm{O}$ equivalente ao exame supletivo de ensino médio brasileiro.
} 
do curso de Bachillerato realizado. Existem 3 (três) áreas de realização do Bachillerato: Artes, Humanidades e Ciências Sociais, e Ciências e Tecnologia. A duração dos cursos de Bachillerato é de 3 (três) anos e eles podem ser realizados no formato presencial ou à distância. Assim como no Brasil, os cursos realizados na modalidade de Educação a Distância, não gozam do mesmo prestígio social que os cursos presenciais.

Por outro lado, o mercado de trabalho espanhol, como no caso anterior (cursos de enseñanzas deportivas, cursos de artes plásticas, ou cursos de desenho), também considera que a formação recebida pelo jovem espanhol, caso ele faça a opção por um curso de formação profissional de nível médio (FP I), já é suficiente para que esse jovem ingresse no mercado laboral espanhol, porém, também como no Brasil, a formação profissional de nível médio (FP I) possui menos prestígio social do que a realização do Bachillerato, em qualquer área.

Feita a opção pelos cursos de Bachillerato, ao terminá-lo, com sucesso, o jovem espanhol tem duas opções, caso queira continuar os seus estudos em nível superior. A primeira opção é ingressar na Universidade em áreas afins ao curso de Bachillerato realizado $^{20}$. A outra opção é encaminhar-se para um curso de formação profissional de nível superior (FP II). A proporção atual entre essas duas opções é de que $70 \%$ dos jovens espanhóis, quando chegam nesse momento de suas vidas acadêmicas, fazem a opção de ingressar na Universidade. Os outros 30\% fazem a opção de cursar programas de formação profissional de nível superior (FP II).

Assim como no Brasil, o número de vagas nas universidades públicas espanholas é menor do que o número de jovens que desejam cursá-la ${ }^{21}$. Assim, na Espanha, a forma de acesso à universidade pública é por meio de uma prova de acesso (prueba de selectividad ${ }^{22}$ ) e da nota média das disciplinas cursadas no Bachillerato $^{23}$. Por outro lado, a Espanha não adota o sistema de cotas para acesso ao ensino superior para o jovem, na chamada "idade apropriada" (16, 17 ou 18 anos), ingressar no ensino superior, ao passo que no Brasil já existe, pelo menos no sistema federal público de

${ }^{20}$ Sobre a transição do Bachillerato para a Universidade espanhola, ver, por exemplo Guàrdia I Olmos (2006).

${ }^{21}$ Necessário se faz destacar que as universidades públicas espanholas não são gratuitas.

${ }^{22} \mathrm{O}$ equivalente aos vestibulares brasileiros.

${ }^{23}$ Existe uma fórmula própria para o cálculo da nota final (uma espécie de "nota de acesso"), que não é objeto central da discussão desse artigo. 
ensino superior, formas regulamentadas de acesso ao mesmo, denominadas, popularmente, como sistema de $\operatorname{cotas}^{24}$.

$\mathrm{Na}$ Espanha, também existem outros caminhos que o jovem espanhol pode trilhar para ingressar na Universidade sem ter feito, necessariamente, o curso de Bachillerato. Um desses caminhos é o de ingressar, a partir do término com sucesso da Educación Secundaria Obligatoria (ESO), em um programa de formação profissional de nível médio (FP I). Concluído esse curso com sucesso (o FP I), o(a) aluno(a) está formalmente apto a participar de todo o processo seletivo para ingresso na Universidade pública espanhola.

O terceiro caminho de acesso para a universidade pública espanhola não se direciona aos jovens, visto que trata-se de uma forma de acesso em função da idade. Adultos maiores de 25 anos possuem um número de vagas especificamente destinados à eles, assim como existe um outro número de vagas destinadas exclusivamente aos adultos maiores de 40 anos e também um número de vagas destinadas exclusivamente aos adultos maiores de 45 anos. Visto que o número de vagas destinadas à esses segmentos são menores que a demanda existente, também para esse caminho existem as provas de acesso (pruebas de selectividad), porém com um nível de dificuldade menor do que as provas aplicadas aos jovens menores de $25 \operatorname{anos}^{25}$.

Para os jovens que não lograram êxito em obter a titulação referente ao término com sucesso da Educación Secundaria Obligatoria (ESO), os jovens denominados "não-titulados", as portas da universidade pública espanhola não estão irremediavelmente fechadas. Ainda existe o caminho, para os jovens de 16 a $24 \operatorname{anos}^{26}$, de se fazer, inicialmente, um programa de formação profissional de nível básico (FP 0), depois um programa de formação profissional de nível médio (FP I) e, em seguida, um programa de formação profissional de nível superior (FP II). Concluído com sucesso esse último (FP II), o jovem espanhol também está formalmente apto a participar de todo o processo seletivo para ingresso na universidade pública espanhola ${ }^{27}$. Há que se

${ }^{24}$ Sobre o caminho percorrido para o estabelecimento do sistema de cotas para acesso ao ensino superior no Brasil e no mundo, anteriormente à regulamentação brasileira para o ingresso nas universidades e institutos federais de ensino superior no Brasil, ver, entre outros, Brandão, 2005.

${ }^{25}$ Podemos dizer que trata-se de uma espécie de sistema de cotas para acesso à universidade pública espanhola, onde a idade é o referencial principal. Segundo informações colhidas, as provas de acesso são mais fáceis para o grupo dos adultos acima de 45 anos, um pouco mais difíceis para o grupo dos adultos acima de 40 anos e, ainda, mais difíceis para o grupo dos adultos acima de 25 anos.

${ }^{26}$ A partir dos 25 anos, o jovem/adulto já faz parte do grupo de maiores de 25 anos, portanto com a opção de ingressar na universidade pública espanhola em função de sua idade.

${ }^{27}$ Neste artigo, insistimos sempre em nos referirmos à universidade pública pois, na realidade espanhola, a quantidade de vagas ofertadas pelas universidades públicas é significativamente maior do que a 
ressaltar porém que, a passagem de um curso à outro (o acesso ao curso seguinte) somente é permitido após a aprovação em provas de acesso ao curso pretendido.

Tendo descrito todos esses caminhos para acesso à universidade pública espanhola, pode parecer, à primeira vista, que o sistema educativo espanhol privilegia excessivamente a questão da idade. Porém, à nosso ver, essa não é uma interpretação correta. Entendemos que o sistema educacional espanhol parte de uma concepção em que um maior número de pessoas deve ter acesso às universidades públicas espanholas, independentemente da idade e, principalmente, independentemente do percurso escolar realizado até o ingresso na universidade.

\section{Diferenças e similitudes}

Da maneira como está organizado, o sistema de ensino espanhol faz com que a Espanha, em termos de desempenho no PISA, quando comparado com o Brasil, esteja muito à frente. Apenas à título de ilustração, no ano 2000 (primeiro ano de participação do Brasil no PISA), enquanto a Espanha obteve a posição $n^{\circ} 19$, num conjunto de 32 países, o Brasil ficou com a última colocação. Em 2009, com a participação de 61 países (quase o dobro, portanto), a Espanha piorou e obteve a posição $n^{\circ} 32$, porém, o Brasil piorou mais e ficou na posição $n^{\circ}$ 50. Por fim, em 2012, já com a participação de 65 países, a Espanha manteve a posição $n^{\circ} 32$ e o Brasil caiu para a posição $n^{\circ} 57$.

É claro que não podemos nos deter em apenas um referencial para realizarmos a nossa análise. Nesse sentido, acreditamos que as informações/constatações mais importantes para demonstrar que a educação espanhola está muito à frente da brasileira são: a) não existe evasão escolar na Educação Básica espanhola; b) não existe analfabetismo na Espanha ${ }^{28}$, e c) a Educação Básica, assim como em outros países desenvolvidos, é oferecida em tempo integral.

Por outro lado, podemos identificar algumas diferenças que consideramos importantes. A primeira delas é a definição formal e legal (na "letra" da lei) de um número objetivo de alunos por professor em sala de aula, em função do nível de ensino. Quando da elaboração da atual Lei de Diretrizes e Bases da Educação Nacional (LDB Lei $n^{\circ}$ 9.394/96), tivemos a oportunidade de também fazermos essa definição para a

quantidade de vagas oferecidas pelas universidades privadas espanholas, além do fato de que essas últimas (as universidades privadas espanholas) são muito caras no contexto desse país.

${ }^{28}$ Segundo informações colhidas in loco, atualmente, o analfabetismo existente na Espanha está concentrado e limitado ao grupo dos imigrantes, especialmente do leste europeu. 
educação brasileira. Não só não o fizemos naquele momento (de 1988 a 1996, período em que a atual LDB brasileira tramitou no Congresso Nacional) como, pior, também não fizemos até agora, apesar da atual LDB já ter sofrido mais de uma centena de modificações em seus quase 22 anos de existência (BRANDÃO, 2015, p. 11-16).

Outra questão que consideramos importante quando procuramos delinear algumas diferenças entre a organização e estruturação do sistema de ensino espanhol e o sistema de ensino brasileiro refere-se à questão da escola de tempo integral. Essa ideia já faz parte da cultura educacional espanhola (e europeia) a muito mais tempo do que da cultura educacional brasileira. Enquanto no Brasil ainda discutimos se teremos dinheiro para a escola em tempo integral, os países desenvolvidos já chegaram a conclusão de que a escola em tempo integral é muito mais "barata" do que, por exemplo, a resolução de problemas sociais decorrentes da "ausência" da criança e do jovem na escola em tempo integral, ou seja, além do lugar da criança e do jovem ser na escola (e não na rua), sua presença deve ser em tempo integral.

Uma outra questão refere-se à obrigatoriedade escolar. Nesse ponto, ao passo que na Espanha a obrigatoriedade escolar é dos 4 até os 16 anos, no Brasil, a partir de 2017, a obrigatoriedade escolar será dos 4 aos 17 anos. Numericamente as diferenças são pouco significativas, assim, a questão passa a ser de que, na Espanha, essa obrigatoriedade já existe há quase uma década e, no Brasil, a obrigatoriedade descrita existe apenas a partir de 2017.

Por fim, uma outra diferença que consideramos significativa refere-se aos diferentes percursos formativos que o jovem espanhol pode trilhar para aceder à Universidade, ao passo que no Brasil, o caminho da formação profissional técnica coloca-se em oposição (e, portanto, em exclusão) ao caminho da formação superior em nossas universidades.

Mas, talvez, a diferença mais significativa que podemos notar entre o sistema de ensino espanhol e o sistema de ensino brasileiro seja na questão da gratuidade. A Educação Básica espanhola pública (dos 4 aos 16 anos) é totalmente gratuita, assim como a Educação Básica brasileira pública (dos 4 aos 17 anos). Então, qual é a diferença? A diferença é que a Educação Básica pública gratuita espanhola é para todos e com qualidade, portanto, alfabetiza todos e não admite evasão. O mesmo, infelizmente, não podemos afirmar sobre a Educação Básica pública e gratuita brasileira. 
Algumas similitudes também podem ser notadas quando comparamos os sistemas de ensino espanhol e brasileiro. Uma delas é o menor prestígio social que a formação profissional goza, quando comparada com a formação de nível superior oferecida pela Universidade. Na verdade, acreditamos que isso não é um problema específico de uma ou outra sociedade, mas sim, um problema inerente às sociedades capitalistas, onde o "trabalho manual" é sempre menos valorizado que o "trabalho intelectual".

Outra similitude é a adoção de algum tipo de sistema de cotas para ingresso na universidade pública. Vimos que, na Espanha, a definição dos grupos a serem beneficiados por cotas tem como referencial principal a idade, ao passo que no Brasil, a definição dos grupos a serem beneficiados por cotas possuem outros e diferenciados parâmetros (etnia, origem escolar, etc). Entendemos que a definição dos parâmetros a serem utilizados para um sistema de cotas de ingresso no ensino superior público está diretamente relacionado com as diferenças que esse sistema visa sanar, portanto, trata-se de questão intrínseca à cada sociedade ${ }^{29}$.

\section{Considerações finais}

Em momento algum de nossa pesquisa tivemos a intenção de concluir que o sistema de ensino espanhol é melhor, igual ou pior do que o sistema de ensino brasileiro, em termos de sua organização e estruturação. Uma assertiva dessa natureza seria inverídica dado que cada sistema de ensino possui as suas peculiaridades e está assentado na história e na cultura de sua sociedade. Isso, em termos de organização, estruturação, especialmente em termos de normatizações, currículo e conteúdos. Porém, em termos de qualidade da educação (e aqui estamos nos referindo à educação e não só ao ensino), especialmente se nos concentrarmos na questão do analfabetismo, da evasão escolar e do desenvolvimento da sociedade na qual o sistema de ensino está inserido, não só podemos como devemos dizer com todas as letras: atualmente, o sistema educacional espanhol está muito à frente do sistema educacional brasileiro.

Podemos afirmar isso, entre outros motivos, pelo fato do sistema educacional espanhol adotar a educação de tempo integral para toda a Educação Básica, ao passo que isso não faz parte da realidade educacional brasileira, como um todo. Mesmo que

29 Há que se destacar também que acaba de ser aprovada uma nova estruturação para os cursos de graduação na Espanha (Real Decreto 43/2015, de 02 de fevereiro de 2015), porém, esse não é o foco desse nosso trabalho. 
não tenhamos discutido especificamente a questão da educação de tempo integral, essa proposta, de política educacional pública (mas também como uma proposta pedagógica), está presente não só na Espanha mas em todos os países desenvolvidos. Se esse motivo não fosse suficiente, já está provado por pesquisas educacionais conduzidas por autores das mais diferentes matizes políticas e ideológicas, que lugar de criança é na escola e o mais tempo possível.

É claro que não basta que nossas crianças e jovens estejam na escola. É preciso que as propostas de educação de tempo integral sejam pautadas por projetos pedagógicos construídos coletivamente pela comunidade escolar. Por outro lado, a implantação de escolas em tempo integral exige substanciosos investimentos financeiros. Porém, se queremos que a Educação Básica brasileira melhore, a adoção da educação de tempo integral pode contribuir significativamente para isso.

Para finalizar, necessário se faz ressaltar que não consideramos que a implantação da educação de tempo integral resolverá todos os problemas da educação brasileira, mas, acreditamos sim que a adoção dessa medida em muito contribuiria (desde que pautada por projetos pedagógico construídos coletivamente pela comunidade escolar) para a melhoria da educação brasileira.

Isso não significa dizer que o sistema educacional espanhol não possui problemas. Sim, ele os tem e não são poucos. Por exemplo, segundo eles, a baixa proficiência em língua inglesa, o aumento constante e significativo das anuidades na educação superior pública, o analfabetismo entre os grupos de imigrantes do leste europeu, entre outros. Porém, os problemas educacionais brasileiros, quando comparados com esses problemas educacionais espanhóis, são maiores e piores, seja qual escala utilizemos para compará-los. Porém, não devemos (nem podemos) parar de lutar por uma educação pública, gratuita e de qualidade para todos os brasileiros, pelo contrário, temos que lutar sempre mais.

\section{REFERÊNCIAS}

BRANDÃO, Carlos da Fonseca. LDB passo a passo: Lei de diretrizes e bases da educação nacional, Lei no 9.394/96 comentada e interpretada, artigo por artigo. 6 ed. rev. e ampl. São Paulo: Avercamp, 2018.

BRANDÃO, Carlos da Fonseca. As cotas na universidade pública brasileira: será esse o caminho? Campinas: Autores Associados, 2005 (Coleção Polêmicas de nosso tempo, 92). 
CARVALHO, Elma Júlia Gonçalves de. Estudos comparados em educação: novos enfoques teórico-metodológicos. Acta Scientiarum, Maringá, v. 36, n. 1, p. 129-141, jan./jun., 2014.

CRUZ, Manuel Fernández. El pacto educativo en España: argumentos para el debate. Sevilla: Fundación ECOEM, 2008.

DAVIES, Nicholas. Legislação educacional federal básica. São Paulo: Cortez, 2004.

FRANCO, Maria Aparecida Ciavatta. Estudos comparados em educação na América Latina: uma discussão teórico-metodológica a partir da questão do outro. In:

PUIGGRÓS, Adriana.; BERTUSSI, Guadelupe Teresinha.; FRANCO, Maria Aparecida Ciavatta (Orgs.). Estudos comparados e educação na América Latina. São Paulo: Livros do Tatu/Cortez, 1992 (Coleção Educação hoje e amanhã).

GUÀRDIA I OLMOS, Joan. La declaración de Bolonia. Sevilla: Fundación ECOEM, 2006.

KANDEL, Isaac Leon. Studies in comparative education. Boston: Houghton Mifflin Company, 1933.

LIMA, Licínio Carlos Viana da Silva; AFONSO, Almerindo Janela Gonçalves.

Democratização, modernização, neoliberalismo. Porto: Edições Afrontamento, 2002 (Coleção Biblioteca das Ciências do Homem).

\section{Como citar este artigo:}

BRANDÃO, Carlos da Fonseca. A estrutura e a organização da educação básica na Espanha: suas diferenças e similitudes com a educação básica brasileira. Revista IberoAmericana de Estudos em Educação, Araraquara, v. 13, n. 4, p. 1552-1567, out./dez., 2018. E-ISSN: 1982-5587. DOI: 10.21723/riaee.unesp.v13.n4.out/dez.2018.11591

Submissão em: $24 / 07 / 2018$

Aprovação final em: 20/09/2018 